\title{
ADAPTABILITY OF WHEAT GENOTYPES UNDER MIXED MODEL METHODOLOGY FOR NORTH EASTERN PLAINS ZONE OF THE COUNTRY
}

\author{
Ajay Verma ${ }^{3 *}$, J. Crossa ${ }^{1}$, M. Vargas ${ }^{1}$, A.K. Joshi ${ }^{1}$, G.P. $\operatorname{Singh}^{3}$ \\ ${ }^{1}$ Senior Biometrician \& Senior Statistician, CIMMYT, Mexico \\ ${ }^{2}$ Director, CIMMYT Regional Office for South Asia, New Delhi \\ ${ }^{3}$ ICAR-Indian Institute of Wheat \& Barley Research, Post Bag \# 158 Agrasain Marg, Karnal 132001 (Haryana), India \\ Received - September 16, 2019; Revision - October 05 , 2019; Accepted - October 11, 2019 \\ Available Online - October 15, 2019
}

DOI: http://dx.doi.org/10.18006/2019.7(5).468.476

KEYWORDS
HMRPGV
RPGV
HMGV
REML/BLUP
Mixed model

\begin{abstract}
Best linear unbiased predictors of wheat genotypes were analysed as per analytic measures of adaptability for the North Eastern Plains zone of the country under mixed model framework. Among the tested genotypes, genotype K1006 had better adaptation while HD2733 \& HD2967 were of specific adaptability during the cropping season of 2016-17. Biplot analysis based on first two significant principal components, accounted for $72.2 \%$ of total GxE interaction sum of squares, observed stable performance of HD2967 and DBW187 genotypes while K1007 and HD2733 would be suitable for specific adaptations. Further, genotypes HD2967, DBW187 and HD3219 had expressed specific adaptation to Varanasi, Faizabad and Dumka, whereas K0307 and DBW39 were better adapted to conditions of Coochbehar \& Chianki. Bikramganj with Manichak, Coochbehar with Chianki, Varanasi with Faizabad, Banka with Sabour and Bardwan maintained acute angles therefore would show similar performance of genotypes. Better adaptable genotypes with higher yield were HD2733, PBW762, HD3249 \& DBW223 as per year cropping season of 2017-18. Biplot analysis identified HD2967, DBW233, HD3254 along with PBW762 and DBW39 genotypes of stable performance. Genotypes WH1218, DBW223, HD2733, HD3249 and DBW221 expressed unstable performance. Harmonic means of the relative performance of predicted genetic values by BLUP is suitable to identify the better adaptive genotypes with high yield.
\end{abstract}

* Corresponding author

E-mail: ajay.verma1@icar.gov.in (Ajay Verma)

Peer review under responsibility of Journal of Experimental Biology and Agricultural Sciences.

Production and Hosting by Horizon Publisher India [HPI] (http://www.horizonpublisherindia.in/).

All rights reserved.
All the articles published by Journal of Experimental Biology and Agricultural Sciences are licensed under a Creative Commons Attribution-NonCommercial 4.0 International License Based on a work at www.jebas.org.

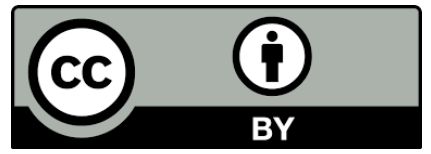




\section{Introduction}

Major objective of a wheat improvement program of any country is to identify promising genotypes which represent yield advantage relative to established check varieties (Crespo et al., 2017). Efficiency of a breeding program is judged by positive changes in yield performance over time (de Oliveira et al., 2017). Main concern in the selection process is to exploit $\mathrm{G} \times \mathrm{E}$ interaction effects so as to reduce the degree of uncertainty in the promotion process for broad or specific adaptability (Burgueño et al., 2011; Silva et al., 2014). Recently linear mixed model analysis of plant breeding experiments under multi environments trials has proved efficient and widely used (Friesen et al., 2016).

Focus of MET analysis is to select the better performing genotypes, based on their yield rankings, owing to random performance of genotypes and consequent use of BLUPs is justified (Gogel et al., 2018). BLUPs maximize the correlation between the realized values and true values (Piepho et al., 2008). Full multivariate BLUP model utilizes all information along with variance heterogeneity (Kleinknecht et al., 2011). Factor analytic
(FA) model with sufficient multiplicative terms is computationally robust (Smith \& Cullis, 2018) and superiority of the Factor Analytic model in a breeding program had been demonstrated by Nuvunga et al. (2018). North eastern plains zone of India comprises eastern Uttar Pradesh, Bihar, Jharkhand, Assam and plains of West Bengal. Wheat is cultivated under highly diverse situations in around 8 million ha area. Among different wheat growing zones, this zone occupies $27 \%$ of total wheat area and accounts for $22 \%$ of the total wheat production in the country. The prime objective was to study adaptability of wheat genotypes by analytic measures under mixed models methodology.

\section{Materials and Methods}

Seven advanced wheat genotypes were evaluated under multi environments trials at 14 major locations of the zone and fifteen advanced wheat genotypes were at thirteen major locations of the zone during 2016-17 and 2017-18 cropping seasons respectively (Figure 1). Field trials were laid out in Randomized Block Design with three replications and recommended agronomical

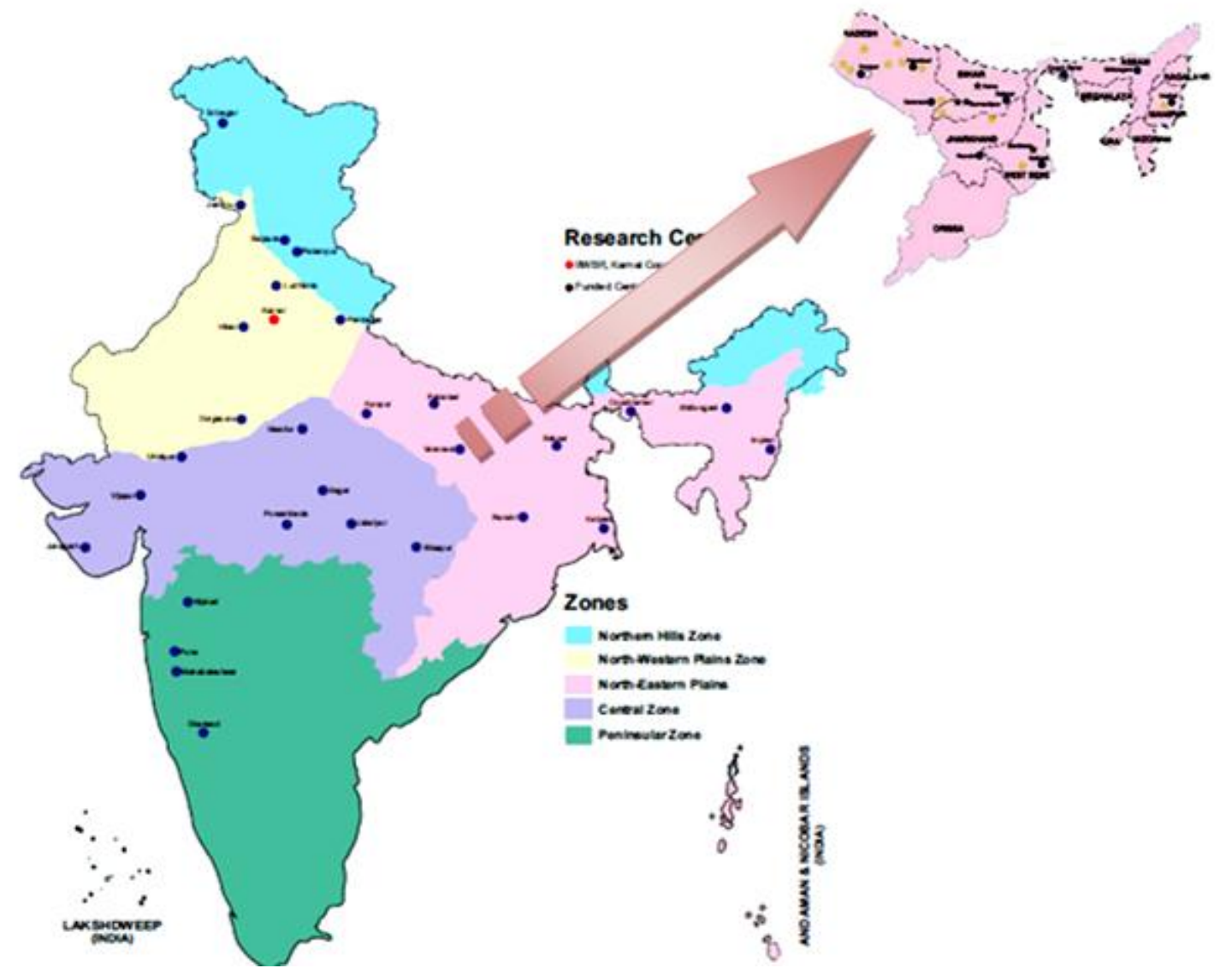

Figure 1: Agro climatics zones for wheat cultivation in country

Journal of Experimental Biology and Agricultural Sciences http://www.jebas.org 
Table 1 Parentage details of wheat genotypes and environments (2016-17)

\begin{tabular}{|c|c|c|c|c|c|}
\hline Genotype & Parentage & Locations & Latitude & Longitude & Altitude (m) \\
\hline DBW187 & $\begin{array}{l}\text { (NAC/TH.AC//3*PVN/3/MIRLO/BUC/4/2*PASTOR/ } \\
\text { 5/KACHU/6/KACHU) }\end{array}$ & Araul & $26^{\circ} 54^{\prime} \mathrm{N}$ & $80^{\circ} 01^{\prime} \mathrm{E}$ & 139 \\
\hline HD3219 & (PBW343/HD2879) & Banka & $24^{\circ} 88^{\prime} \mathrm{N}$ & $86^{\circ} 91^{\prime} \mathrm{E}$ & 83 \\
\hline HD2733 & (ATTILA/3/TUI/CARC//CHEN/CHTO/4/ATTILA) & Barabanki & $26^{\circ} 94^{\prime} \mathrm{N}$ & $81^{\circ} 37^{\prime} \mathrm{E}$ & 119 \\
\hline K0307 & (K8321/UP2003) & Bikramganj & $25^{\circ} 22^{\prime} \mathrm{N}$ & $84^{\circ} 26^{\prime} \mathrm{E}$ & 92 \\
\hline DBW39 & (ATTILA/HUI) & Burdwan & $23^{\circ} 13^{\prime} \mathrm{N}$ & $87^{\circ} 51^{\prime} \mathrm{E}$ & 38 \\
\hline K1006 & (PBW343/HP1731) & Coochbehar & $26^{\circ} 19^{\prime} \mathrm{N}$ & $89^{\circ} 27^{\prime} \mathrm{E}$ & 43 \\
\hline \multirow[t]{10}{*}{ HD2967 } & (ALD/CUC//URES/HD2160M/HD2278) & Chianki & $26^{\circ} 87^{\prime} \mathrm{N}$ & $91^{\circ} 48^{\prime} \mathrm{E}$ & 228.6 \\
\hline & & Dumka & $24^{\circ} 16^{\prime} \mathrm{N}$ & $87^{\circ} 14^{\prime} \mathrm{E}$ & 137 \\
\hline & & Faizabad & $26^{\circ} 77^{\prime} \mathrm{N}$ & $82^{\circ} 14^{\prime} \mathrm{E}$ & 106 \\
\hline & & Ghazipur & $25^{\circ} 58^{\prime} \mathrm{N}$ & $83^{\circ} 59^{\prime} \mathrm{E}$ & 72 \\
\hline & & Kanpur & $26^{\circ} 26^{\prime} \mathrm{N}$ & $80^{\circ} 19^{\prime} \mathrm{E}$ & 133 \\
\hline & & Manikchak & $25^{\circ} 4^{\prime} \mathrm{N}$ & $87^{\circ} 54^{\prime} \mathrm{E}$ & 33 \\
\hline & & Ranchi & $23^{\circ} 20^{\prime} \mathrm{N}$ & $85^{\circ} 18^{\prime} \mathrm{E}$ & 644 \\
\hline & & Sabour & $25^{\circ} 23^{\prime} \mathrm{N}$ & $87^{\circ} 04^{\prime} \mathrm{E}$ & 42 \\
\hline & & Shillongani & $24^{\circ} 38^{\prime} \mathrm{N}$ & $77^{\circ} 13^{\prime} \mathrm{E}$ & 50.2 \\
\hline & & Varanasi & $25^{\circ} 19^{\prime} \mathrm{N}$ & $82^{\circ} 59^{\prime} \mathrm{E}$ & 84 \\
\hline
\end{tabular}

Table 2 Parentage details of wheat genotypes and environments (2017-18)

\begin{tabular}{|clcccc|}
\hline Genotype & \multicolumn{1}{c}{ Parentage } & Locations & Latitude & Longitude & Altitude (m) \\
\hline DBW233 & (CHIBIA//PRLII/CM65531/3/SKAUZ/BAV92/4/MUNAL\#1) & Kalyani & $22^{\circ} 58^{\prime} \mathrm{N}$ & $88^{\circ} 26^{\prime} \mathrm{E}$ & 16 \\
\hline HD3249 & (PBW343*2/KUKUNA//SRTU/3/PBW343*2/KHVAKI) & Burdwan & $23^{\circ} 13^{\prime} \mathrm{N}$ & $87^{\circ} 51^{\prime} \mathrm{E}$ & 38 \\
\hline HD3254 & $($ CL1705/HD2687) & Manichak & $25^{\circ} 4^{\prime} \mathrm{N}$ & $87^{\circ} 54^{\prime} \mathrm{E}$ & 33 \\
\hline DBW221 & $($ (36IBWSN284/22ESWYT28) & Pusa & $25^{\circ} 98^{\prime} \mathrm{N}$ & $85^{\circ} 67^{\prime} \mathrm{E}$ & 56 \\
\hline K1601 & $($ K9107/DBW14) & Purnea & $25^{\circ} 46^{\prime} \mathrm{N}$ & $87^{\circ} 28^{\prime} \mathrm{E}$ & 43 \\
\hline PBW769 & $\begin{array}{l}\text { (ATTILA/3*BCN/3/CROC_1/AE.SQUARROSA(224)//OPATA/4/CHI } \\
\text { BIA/PRLII/CM65531/3/SKAUZ/BAV92/4/MUNAL\#1) }\end{array}$ & Sabour & $25^{\circ} 23^{\prime} \mathrm{N}$ & $87^{\circ} 04^{\prime} \mathrm{E}$ & 42 \\
\hline DBW187 & (NAC/TH.AC//3*PVN/3/MIRLO/BUC/4/2*PASTOR/5/KACHU/6/KA & Ranchi & $23^{\circ} 20^{\prime} \mathrm{N}$ & $85^{\circ} 18^{\prime} \mathrm{E}$ & 644 \\
\hline DBW223 & (PBW550/CBW38) & Dumka & $24^{\circ} 16^{\prime} \mathrm{N}$ & $87^{\circ} 14^{\prime} \mathrm{E}$ & 137 \\
\hline PBW762 & (YR5/6*AVOCET//2*PBW550) & Basti & $26^{\circ} 49^{\prime} \mathrm{N}$ & $82^{\circ} 45^{\prime} \mathrm{E}$ & 85 \\
\hline WH1218 & (KA/NAC//TRCH/3/VORB) & Varanasi & $25^{\circ} 19^{\prime} \mathrm{N}$ & $82^{\circ} 59^{\prime} \mathrm{E}$ & 84 \\
\hline K1006 & (PBW343/HP1731) & Gorakhpur & $26^{\circ} 45^{\prime} \mathrm{N}$ & $83^{\circ} 22^{\prime} \mathrm{E}$ & 84 \\
\hline HD2733 & (ATTILA/3/TUI/CARC//CHEN/CHTO/4/ATTILA) & Araul & $26^{\circ} 54^{\prime} \mathrm{N}$ & $80^{\circ} 01^{\prime} \mathrm{E}$ & 139 \\
\hline DBW39 & (ATTILA/HUI) & Kanpur & $26^{\circ} 26^{\prime} \mathrm{N}$ & $80^{\circ} 19^{\prime} \mathrm{E}$ & 133 \\
\hline HD2967 & (ALD/CUC//URES/HD2160M/HD2278) & & & \\
\hline K0307 & (K8321/UP2003) & & \\
\hline
\end{tabular}

interventions followed to harvest the good crop. More over the yield were analysed further to generate useful information. Details of genotypes and locations were reflected in tables $1 \& 2$ for ready reference. Mixed model to estimate fixed effects of blocks (b), random effects of genotypes (g) and interaction GxE effects (c) along with random errors $(\varepsilon)$ described as

$\mathrm{Y}=\mathrm{Xb}+\mathrm{Zg}+\mathrm{Wc}+\varepsilon$ 
Where incidence matrices were $\mathrm{X}, \mathrm{Z}$ and $\mathrm{W}$ respectively (Resende \& Duarte, 2007).

Simple and effective measure for adaptability is calculated as the relative performance of genetic values (PRVG) across environments (Resende, 2007). Moreover measure MHVG method (harmonic mean of genetic values), based on the harmonic mean of the genotypic values across in different environments (Resende, 2007). Lower the standard deviation of genotypic performance across environments, the greater is the harmonic mean of its genotypic values. Another measure based on the harmonic mean of the relative performance of the genotypic values (MHPRVG) under the mixed models analysis (Resende, 2007) for the simultaneous analysis of stability, adaptability and yield. Consequently, the selection for higher values of the harmonic mean results in selection for both yield and stability.

$\mathrm{PRVG}_{\mathrm{ij}}=\mathrm{VG}_{\mathrm{ij}} / \mathrm{VG}_{\mathrm{i}}$

$\mathrm{MHVG}_{\mathrm{i}}=$ Number of environments $/ \sum_{i=1}^{k} \frac{1}{X_{i}}$

$\mathrm{MHPRVG}_{\mathrm{i} .}=\mathrm{n} / \sum_{j=1}^{k} \frac{1}{P R V G_{i j}}$

$\mathrm{VG}_{\mathrm{ij}}$ is the genotypic value of the $\mathrm{i}$ genotype, in the $\mathrm{j}$ environment, expressed as a proportion of the average in this environment. To facilitate interpretation, PRVG and MHPRVG values were multiplied by the general mean (GM), to provide results in the same magnitude as of the average wheat yield (Verardi et al., 2009). Estimation of the variance components were carried out by ASReml-R package using residual maximum likelihood (REML) along with estimation / prediction of the fixed as well as random effects (Cullis et al., 2014).

\section{Results and discussion}

\subsection{First year of study (2016-17)}

Average yield of genotypes as per BLUP's identified in K1006 \&
DBW39 as desirable while HD2967 along with HD2733 expressed low yields (Table 3). Harmonic mean of genotypes values selected K1006 \& DBW39 as high yielders at the same lower yield of HD2733 \& HD2967. Mean and Harmonic yield of studied genotypes based on BLUE's pointed towards DBW187 and HD3219. PRVG as well as PRVG*GM pointed out K1006 \& DBW39 as of better adaptable genotypes whereas HD2733 \& HD2967 with low adaptability across locations of North Eastern Plains Zone of the country. Recent analytic measures HMPRVG and HMPRVG*GM marked K1006 \& K0307 genotypes of high yield and better adaptability across zone. In general an agreement was observed in the classification of wheat genotypes, based on BLUP, MHVG, PRVG, MHPRVG and average yield (Table 3). Genotypic values can be predicted by measures based on Harmonic means that cares of adaptability along with yield (Verardi et al., 2009). Under mixed model methodology MHPRVG measures observed as an efficient for wheat improvement programs as mentioned by Mendes et al 2012 for other crops (Verardi et al., 2009; Mendes et al., 2012).

Large variation in average yield of wheat genotypes had observed on the BLUE and BLUP across zone (Figure 2). More over consistent lower values had seen for genotypes based on BLUE except for HD3219 \& DBW187. However the heights standard error of genotypes were at par with fixed and random effects assumptions of genotypes behavior.

First two significant principal components accounted for $72.2 \%$ of total GxE interaction sum of squares (Figure 4). Biplot analysis pointed out stable performance of genotypes or environments occupy positions near the cross section of coordinate system and vice versa for unstable behavior (Durate \& Vencovsky, 1999). According to Yang \& Kang (2003) specific adaptability of genotypes justified by close proximity near to environment.

Genotypes HD2967 and DBW187 would be of stable performance

Table 3 Adaptability measures of wheat genotypes based on BLUP's (2016-17)

\begin{tabular}{llll|llllllllllll} 
BLUP & Rk & HM-UP & Rk & BLUE & Rk & HM-UE & Rk & PRVG & Rk & PRVG*GM & Rk & MHPVRG & Rk & MHPVRG*GM & Rk
\end{tabular}

\begin{tabular}{|ccccccccccccccccc|}
\hline DBW187 & 46.42 & 4 & 44.99 & 4 & 48.84 & 1 & 47.78 & 1 & 0.9954 & 4 & 46.38 & 4 & 0.9839 & 4 & 45.84 & 4 \\
\hline HD3219 & 46.34 & 5 & 44.83 & 5 & 47.20 & 2 & 46.16 & 2 & 0.9935 & 5 & 46.29 & 5 & 0.9806 & 5 & 45.69 & 5 \\
\hline HD2733 & 46.02 & 6 & 44.32 & 7 & 45.74 & 6 & 43.95 & 6 & 0.9835 & 6 & 45.82 & 6 & 0.9727 & 7 & 45.32 & 7 \\
\hline K0307 & 46.76 & 3 & 45.93 & 3 & 46.10 & 4 & 45.32 & 4 & 1.0054 & 3 & 46.84 & 3 & 1.0022 & 2 & 46.69 & 2 \\
\hline DBW39 & 46.76 & 2 & 45.93 & 2 & 45.76 & 5 & 44.64 & 5 & 1.0066 & 2 & 46.90 & 2 & 1.0013 & 3 & 46.65 & 3 \\
\hline K1006 & 48.00 & 1 & 46.64 & 1 & 46.48 & 3 & 45.65 & 3 & 1.0327 & 1 & 48.12 & 1 & 1.0169 & 1 & 47.38 & 1 \\
\hline HD2967 & 45.83 & 7 & 44.50 & 6 & 44.67 & 7 & 43.11 & 7 & 0.9829 & 7 & 45.79 & 7 & 0.9738 & 6 & 45.37 & 6 \\
\hline
\end{tabular}

BLUP, Average of best linear unbiased predictors; HM-UP, harmonic mean of the BLUP values; HM-UE, harmonic mean of the BLUE values; PRVG, genotypic values; GM, overall average; MHPRVG, harmonic mean of the relative performance of the predicted genotypic values; Rk rank of genotypes 
while K1007 and HD2733 would be suitable for specific adaptations (Figure 4). This interpretation is based on distance of genotypes from origin of biplot analysis. Environments of Bardwan, Ranchi, Kanpur and Kaul would be the larger contributors to the $\mathrm{G} \times \mathrm{E}$ interaction of genotypes. On the other hand, Sabour and Shillongani environments would be suitable for stable performance of wheat genotypes.
Genotypes and environments placed close to each other in the biplot have positive associations; this behavior would enable to identify specific zones for relatively similar performance of genotypes. HD2967, DBW187 and HD3219 had a specific adaptation to Varanasi, Faizabad and Dumka environments, whereas K0307 and DBW39 were better adapted genotypes to environments Coochbehar \& Chianki. Genotype HD2733 expressed suitability to Ranchi \& Ghazipur locations.

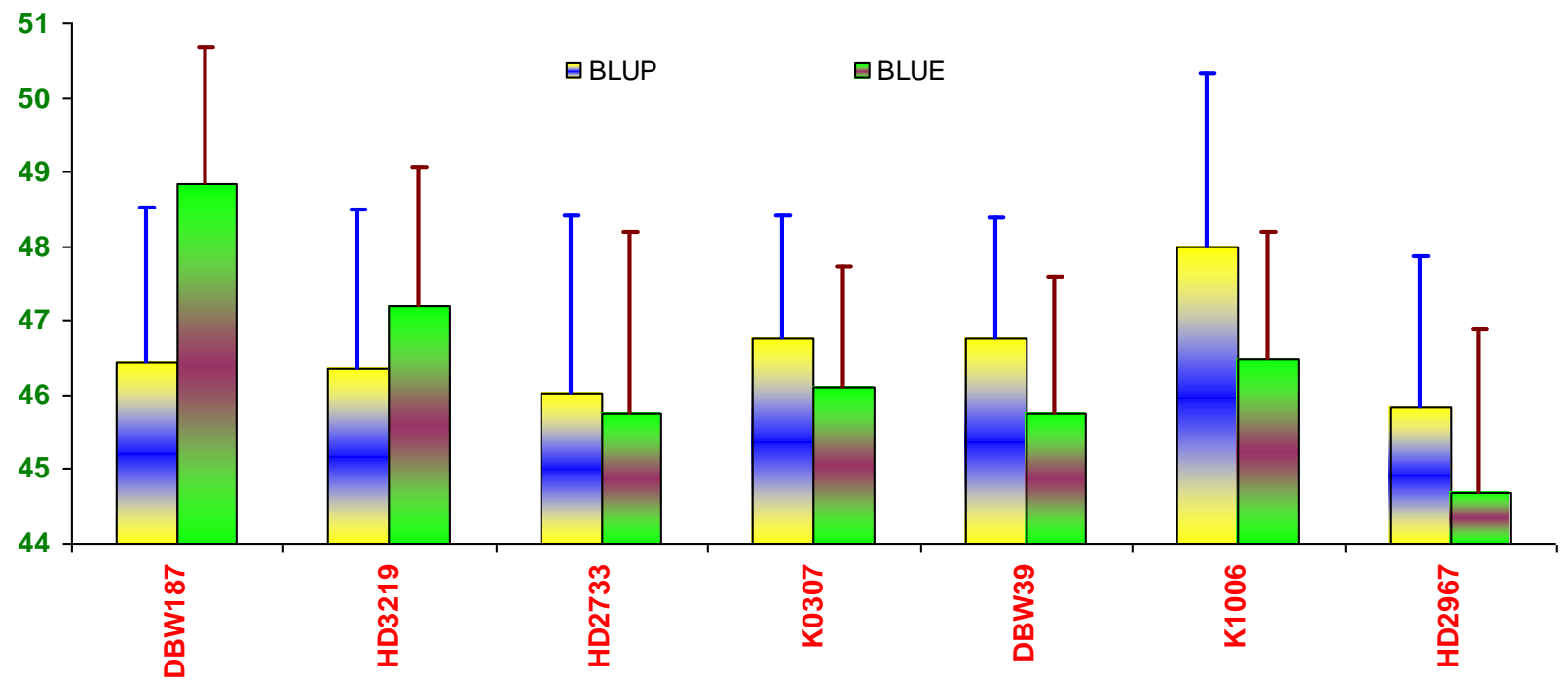

Figure 2 Average yield of wheat genotypes with standard errors (2016-17)

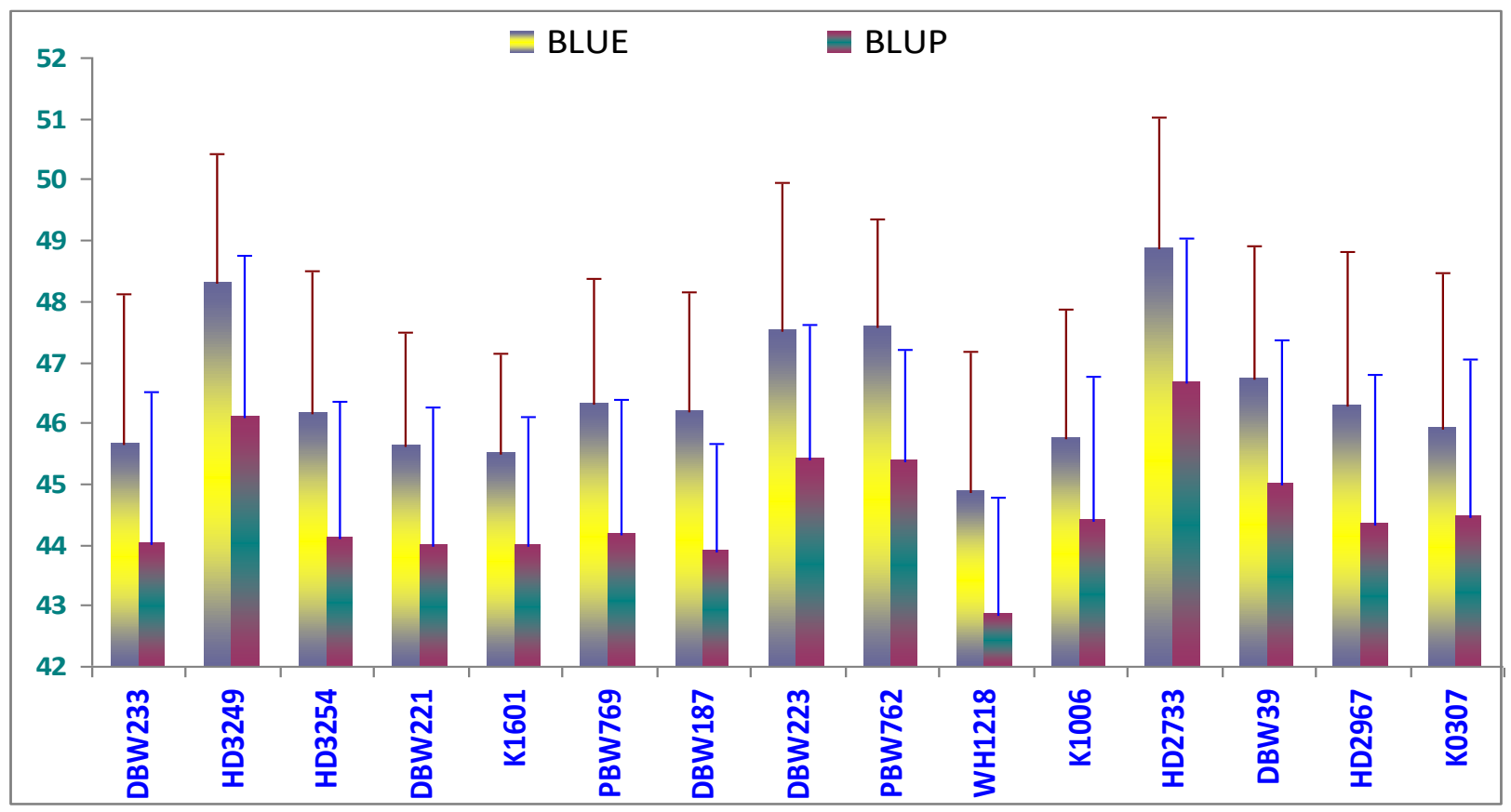

Figure 3 Average yield of wheat genotypes with standard errors (2017-18)

Journal of Experimental Biology and Agricultural Sciences http://www.jebas.org 


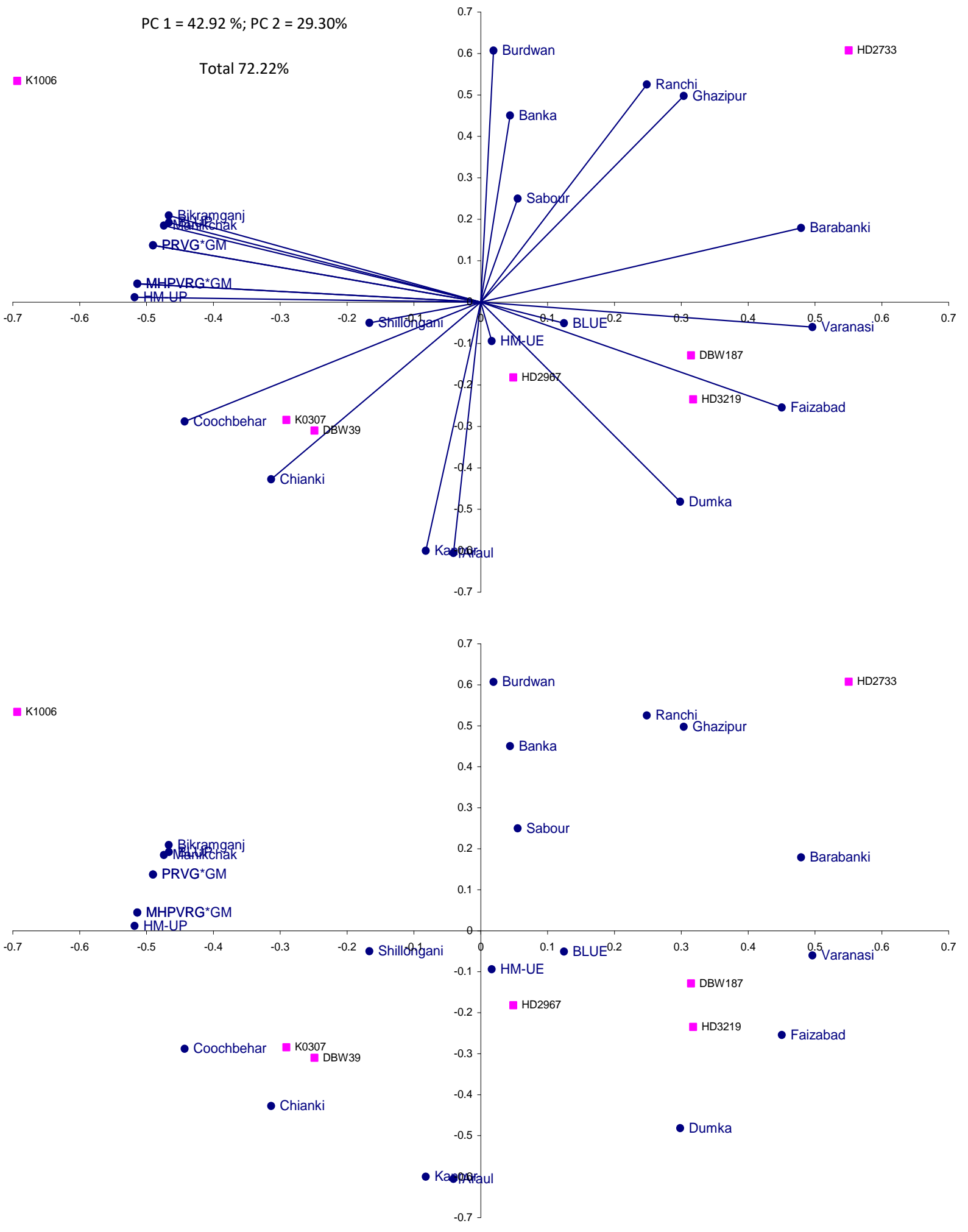

Figure 4 Biplot analysis of BLUP's of genotypes vis-à-vis locations 2016-17

Journal of Experimental Biology and Agricultural Sciences http://www.jebas.org 
Table 4 Adaptability measures of wheat genotypes based on BLUP's (2017-18)

\begin{tabular}{|ccccccccccccc|c|}
\hline & BLUP & Rk & HM-UP & Rk & PRVG & Rk & PRVG*GM & Rk & HMRPVG & Rk & HMRPVG*GM & Rk \\
\hline DBW233 & 44.02 & 11 & 42.58 & 14 & 0.9845 & 14 & 43.89 & 14 & 0.9769 & 14 & 44.59 & 13 \\
\hline HD3249 & 46.10 & 2 & 44.48 & 3 & 1.0299 & 2 & 45.92 & 2 & 1.0226 & 2 & 49.40 & 2 \\
\hline HD3254 & 44.12 & 10 & 43.11 & 8 & 0.9897 & 10 & 44.13 & 10 & 0.9855 & 9 & 45.49 & 8 \\
\hline DBW221 & 44.00 & 12 & 42.82 & 12 & 0.9848 & 13 & 43.90 & 13 & 0.9823 & 12 & 44.81 & 12 \\
\hline K1601 & 43.98 & 13 & 42.80 & 13 & 0.9890 & 11 & 44.09 & 11 & 0.9779 & 13 & 44.49 & 14 \\
\hline PBW769 & 44.17 & 9 & 43.05 & 9 & 0.9914 & 9 & 44.20 & 9 & 0.9846 & 10 & 45.60 & 7 \\
\hline DBW187 & 43.90 & 14 & 43.17 & 6 & 0.9889 & 12 & 44.09 & 12 & 0.9841 & 11 & 45.46 & 9 \\
\hline DBW223 & 45.41 & 3 & 44.30 & 4 & 1.0217 & 4 & 45.55 & 4 & 1.0113 & 4 & 48.07 & 4 \\
\hline PBW762 & 45.38 & 4 & 44.59 & 2 & 1.0220 & 3 & 45.56 & 3 & 1.0171 & 3 & 48.39 & 3 \\
\hline WH1218 & 42.86 & 15 & 42.01 & 15 & 0.9683 & 15 & 43.17 & 15 & 0.9538 & 15 & 42.79 & 15 \\
\hline K1006 & 44.40 & 7 & 43.15 & 7 & 0.9945 & 6 & 44.34 & 6 & 0.9891 & 6 & 45.24 & 11 \\
\hline HD2733 & 46.66 & 1 & 45.43 & 1 & 1.0453 & 1 & 46.60 & 1 & 1.0409 & 1 & 50.87 & 1 \\
\hline DBW39 & 44.98 & 5 & 43.74 & 5 & 1.0057 & 5 & 44.84 & 5 & 1.0042 & 5 & 46.92 & 5 \\
\hline HD2967 & 44.32 & 8 & 42.98 & 11 & 0.9915 & 8 & 44.20 & 8 & 0.9859 & 8 & 45.63 & 6 \\
\hline K0307 & 44.45 & 6 & 43.04 & 10 & 0.9929 & 7 & 44.27 & 7 & 0.9884 & 7 & 45.38 & 10 \\
\hline
\end{tabular}

BLUP, Average of best linear unbiased predictors; HM, harmonic mean of the genotypic values; PRVG, genotypic values; GM, overall average; MHPRVG, harmonic mean of the relative performance of the predicted genotypic values; Rk rank of genotypes

Bikramganj with Manichak, Coochbehar with Chianki, Varanasi with Faizabad, Banka with Sabour and Bardwan would show similar performance of genotypes as expressed acute angles among rays connecting these environments. Kanpur had an angle of 180 with Ranchi likewise Dhumka with Bikramgunj this would express opposite performance of genotypes i.e. K1006 will not be of choice for Dhumka.

\subsection{Second year of study (2017-18)}

Mean of genotypes based on BLUP values identified HD2733, HD3249, DBW223, PBW762 as desirable while WH1218 \& DBW187 as of low yielders. Harmonic mean of genotypes values selected HD2733, PBW762, HD3249, DBW223 as high yielders while WH1218 \& DBW233 showed lowest yield (Table 4). HD2733, HD3249, PBW762, DBW223 genotypes were pointed out by PRVG as well as by $\mathrm{PRVG}^{*} \mathrm{GM}$ as of better adaptable genotypes whereas WH1218 \& DBW233 of low adaptability across locations of North Eastern Plains Zone trials. HMPRVG and HMPRVG*GM marked HD2733, HD3249, PBW762, DBW223 as of high yield and better adaptability across zone for irrigated timely sown cultivation. There was an agreement in the classification of productive wheat genotypes, based on BLUP, MHVG, PRVG, MHPRVG and average yield (Table 4).
Difference had observed among the BLUE and BLUP values of genotypes across zone (Figure 3). More over consistent lower values had seen for genotypes under mixed model analysis. However the heights standard error of genotypes were at par with fixed and random effects assumptions of genotypes behavior.

First two significant principal components accounted for $58.5 \%$ of total GxE interaction sum of squares (Figure 5). Genotypes HD2967, DBW233 and HD3254 were the most stable; however, these were in company with the genotypes PBW762 and DBW39. This conclusion holds because these genotypes were positioned near the origin of the biplot. On the other hand, genotypes WH1218, DBW223, HD2733, HD3249 and DBW221 were the most unstable; that is, these had specific adaptations, because they were more distant from the biplot origin. Environment Manichak was the largest contributor to the phenotypic stability of these genotypes. On the other hand, far positioned environments from the origin in the AMMI2 biplot i.e. Aural, Kalyani, Sabour and Kanpur contributed to the $\mathrm{G} \times \mathrm{E}$ interaction.

Genotypes and environments placed close to each other in the biplot have positive associations; this behavior would enable to identify agronomic zones with relative performance of genotypes. HD2967 had a specific adaptation to environment Manichak, 


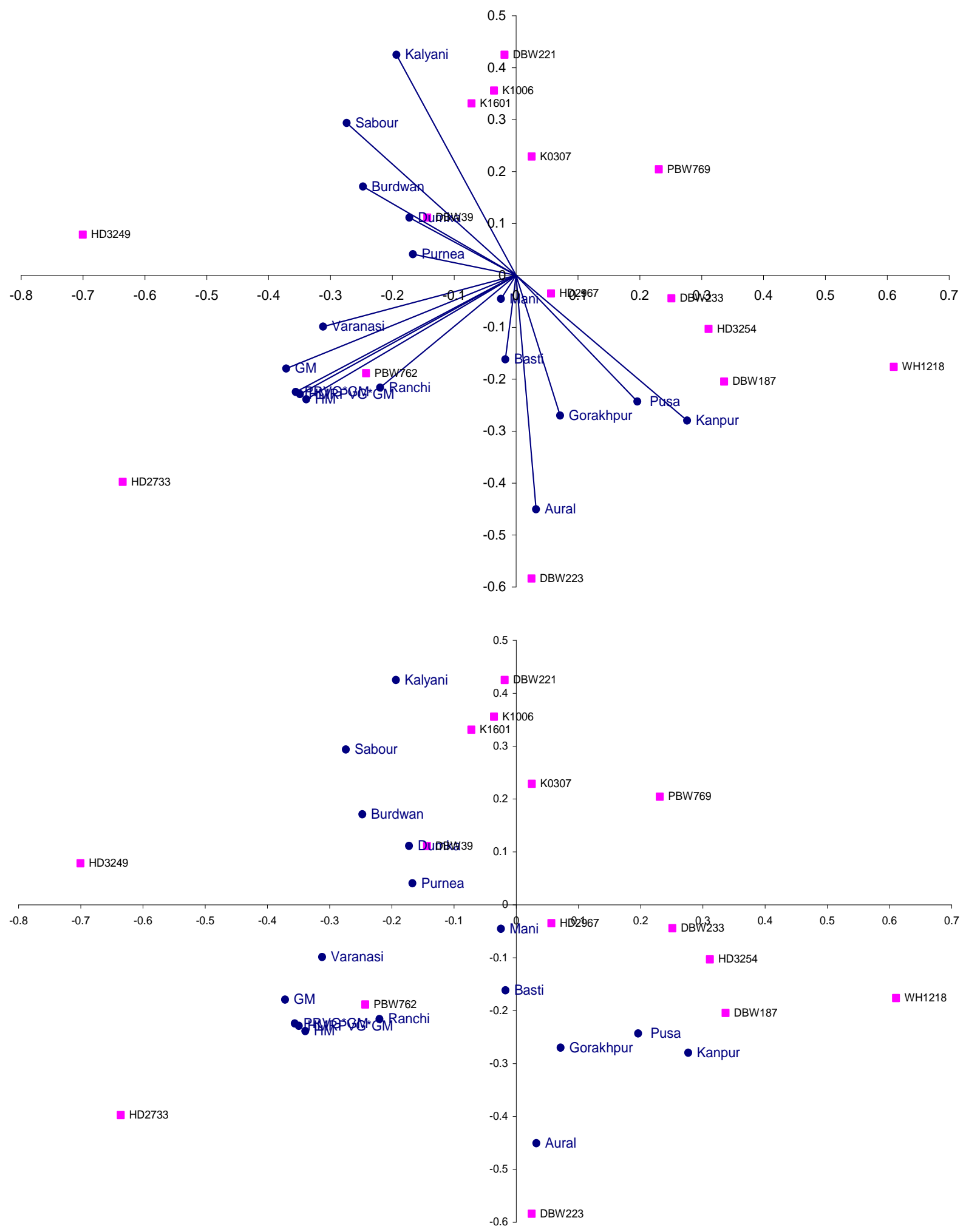

Figure 5 Biplot analysis of BLUP's of genotypes vis-à-vis locations (2017-18)

Journal of Experimental Biology and Agricultural Sciences http://www.jebas.org 
whereas DBW221, K1006 and K1601 were better adapted genotypes to environments Kalyani \& Sabour. Genotype PBW762 expressed suitability to Varanasi \& Ranchi environment conditions.

In general, purpose is to identify wheat genotypes with wide geographic adaptation as well as higher yield along with good average yield even in heterogeneous environments (Murakami \& Cruz, 2004). Although, these conditions are hard to satisfy in order to increase zonal productivity of wheat cereal, now it is imperative to recommend genotypes with specific adaptations (Crespo et al., 2017). Particularly for this important cereal, to ensure food security of country, the identification of these specific positive interactions becomes especially important as there is lot of pressure to improve wheat productivity in North Eastern Plains zone of country under changing environmental conditions.

\section{Conclusions}

Recent measures of adaptability based on harmonic means of the relative performance of genotypes as per their BLUP estimates observed to be suitable to identify the better adaptive genotypes with high yield.

\section{Acknowledgements}

Guidance and financial support extended by Dr RP Singh, CIMMYT Mexico acknowledged by the authors. Efforts of staff, working at various centers, are highly appreciated for field evaluation under coordinated system of wheat.

\section{Conflict of Interest}

No conflict of interest

\section{References}

Burgueño J, Crossa J, Cotes JM, Vicente FS, Das B (2011) Prediction assessment of linear mixed models for multi environment trials. Crop Science 51: 944-954.

Crespo-Herrera LA, Crossa J, Huerta-Espino J, Autrique E, Mondal S, Velu G (2017) Genetic yield gains in CIMMYT's International Elite Spring Wheat Yield Trials by modeling the genotype $\times$ environment interaction. Crop Science 57:789-801.

Cullis BR, Jefferson P, Thompson R, Smith AB (2014) Factor analytic and reduced animal models for the investigation of additive genotype by environment interaction in out crossing plant species with application to a pinus radiata breeding program. Theoretical and Applied Genetics 127:2193-2210.

Duarte JB, Vencovsky R (1999) Interação genótipos x ambientes: uma introdução à análise AMMI. Ribeirão Preto: Soc Bras Genét. Pp. 60.

Friesen LF, Brule-Babel AL, Crow GH, Rothenburger PA (2016) Mixed model and stability analysis of spring wheat genotype yield evaluation data from Manitoba, Canada. Canadian Journal of Plant Science 96 : 305-320.

Gogel BJ, Smith AB, Cullis BR (2018) Comparison of a one and two-stage mixed model analysis of Australia's National Variety Trial Southern Region wheat data. Euphytica 214: 44-64.

Kleinknecht K, Laidig F, Piepho HP, Möhring J (2011) Best linear unbiased prediction (BLUP): Is it beneficial in official variety performance trials?. Biuletyn Oceny Odmian 33:21-33.

Mendes FF, Guimarães LJM, Souza JC, Guimarães PEO, Pacheco CAP, de Machado J RA, Meirelles W F, da Silva A R, Parentoni S (2012) Adaptability and stability of maize varieties using mixed model methodology. Crop Breeding and Applied Biotechnology 12: 111-117.

Murakami DM, Cruz CD (2004) Proposal of methodologies for environment stratification and analysis of genotype adaptability. Crop Breeding and Applied Biotechnology 4:7-11.

Nuvunga JJ, Oliveira LA, Silva CP, Pamplona AKA, Silva AQ, Moura EG, Maleia MP, Balestre M (2018) Adaptability and stability of cotton cultivars (Gossypium hirsutum L. race latifolium H.) using factor analytic model. Genetics and Molecular Research 17 :1-10.

de Oliveira IJ, Atroch AL, Dias MC, Guimarães LJ, de Paulo EOG (2017) Selection of corn cultivars for yield, stability and adaptability in the state of Amazonas, Brazil. Pesquisa Agropecuária Brasileira 52:455-463.

Piepho HP, Möhring J, Melchinger AE, Büchse A (2008) BLUP for phenotypic selection in plant breeding and variety testing. Euphytica 161: 209-228.

Resende MDV (2007) Selegen-reml/blup: statistical system and computerized genetic selection by linear mixed models. Embrapa Florestas, Colombo, PR, Brazil.

Resende MDV, Duarte JB (2007) Precision and quality control in variety trials. Pesquisa Agropecuária Tropical 37: 182-194.

Silva P da, Bisognin DA, Locatelli AB, Storck L (2014) Adaptability and stability of corn hybrids grown for high grain yield. Acta Scientiarum. Agronomy 36:175-181.

Smith AB, Cullis BR (2018) Plant breeding selection tools built on factor analytic mixed models for multi-environment trial data. Euphytica 214:143-161.

Verardi CK, Resende MDZV, Costa RB, Gonçalves PS (2009) Adaptabilidade e estabilidade da produção de borracha e seleção em progênies de seringueira. Pesquisa Agropecuária Brasileira 44: 1277-1282.

Yang W, Kang MS (2003) GGE Biplot Analysis: A Graphical Tool for Breeders, Geneticists, and Agronomists. CRC Press, Boca Raton, FL. 